\title{
Promoting high quality research into priority health needs in Latin America and Caribbean
}

\author{
The region still needs to build its research capacity to inform effective public health policy and \\ practices, say Fabio Zicker and colleagues
}

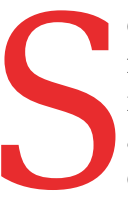

cientific evidence from high quality research studies is important for improving global health and health equity. ${ }^{1}$ In resource constrained settings, regionally relevant knowledge and tools are essential for strengthening the effectiveness of health services and reducing the burden of disease. $^{2}$

Creation of national health research systems focusing on local priorities in Latin America and the Caribbean (LAC) can facilitate high quality research and build research capacity. ${ }^{3}$ Over the past 15 years, overall expenditure on research and development in the region has increased from $0.57 \%$ to $0.8 \%$ of the gross domestic product (GDP). However, this is still far below the level of investment in countries of the Organisation for Economic Cooperation and Development (2.5-2.8\% of GDP). ${ }^{4}$

Although the number of citable health science publications from LAC has tripled, ${ }^{5}$ the relevance and potential of research to address the region's health challenges still need to improve. The disconnect between academic research and healthcare needs in the region is widely recognised. ${ }^{6}$ Overall funding for science and research infrastructure has been vulnerable to social, economic, and political instability. Science funding has been one of the first government budget lines to be cut when there is fiscal

\section{KEY MESSAGES}

- Despite social, economic, and political instability, LAC has increased its research and development expenditure and tripled health related publications in recent years

- Fostering research output relevant to public health relies on priority setting processes, strengthening national research systems, and improving collaboration between the academic community and public health implementers

- Implementation research has an important role in improving the performance of health systems

- Sustainable investment in infrastructure and human resources is necessary for enhancing the contribution of research to public health pressure. ${ }^{7}$ Within this context, some initiatives have been carried out to boost the capacity and relevance of health research in the region. In this article we analyse successes, barriers, and lessons from some of these initiatives.

\section{Strengthening national health research systems}

Growing global recognition of the importance of national health research programmes to improve health systems prompted the Council for Health Research for Development and Pan American Health Organisation (PAHO) to conduct a survey of research systems in 14 countries in the region in 2008. At that time, only six countries had formal research governance and management structures in place, led by either the ministry of health or the ministry of science and technology, and only nine countries reported having established priorities for national health research. ${ }^{8}$ The results were discussed at the First Latin American Conference on Research and Innovation for Health and influenced PAHO's 2009 Policy for Research for Health. ${ }^{3}$

One of the key objectives of the policy was to establish national health research priorities. A 2014 review, five years after the policy was established, showed an increase in the number of LAC countries with research agendas. Fourteen of the 37 countries included in the review had research agendas, with wide variations in terms of objectives, content, methods, and strategic areas. ${ }^{9}$ The study highlighted a continuing need for ministries of health and stakeholders across the region to implement national research priority setting exercises using systematic methods.

\section{Aligning research priorities}

Ministries of health and of science and technology in LAC have steadily increased engagement with healthcare systems by defining priorities and promoting relevant health research. Research initiatives like EVIPnet (Evidence-Informed Policy Network) ${ }^{10}$ and SORT IT (an operational research and training programme) ${ }^{11}$ have been established within the ministries of health of 10 countries. PAHO and WHO have facilitated training, the development of web portals, and the introduction of methods to appraise scientific evidence. The aim of these programmes is to empower policy makers, researchers, and implementers to bridge the gap between knowledge generation and use in policy. The focus has been on areas such as access to high quality maternal and child care, prevention and control of infectious diseases, tuberculosis diagnosis and treatment, and access to high cost medicines. However, in practice, continuous competing conflicts exist between applying current knowledge and generating and testing new knowledge and evidence. ${ }^{3}$

In order to promote research on specific knowledge gaps, the Brazilian Research Program for the Unified Health System has decentralised funding $(\$ 100 \mathrm{~m}$ over 15 years) for research, technology development, and innovation, issuing research calls on priority topics. ${ }^{12}$ The process has included local priority setting exercises managed by state foundations for science and technology support, including policy makers, researchers, implementers, and in some instances patient associations, with the objective of proposing regionally relevant research agendas. This strategy has proved useful in increasing the demand for research on priority problems, including health technology assessment and healthcare management at point of care- for example, the testing, diagnosis, and treatment of tuberculosis at the same health centre.

\section{Improving research quality and standards}

Some of the region's most developed initiatives for strengthening research quality and standards are in the Caribbean. Caribbean academic institutions, in collaboration with the International Clinical Epidemiology Network and the Cochrane Collaboration, have promoted training to improve the quality of public health research. The focus has been on the production of systematic reviews, methods for project planning and evaluation, good clinical practice, and research ethics. The initiatives tap into fellowship programmes sponsored by the Emerging Leaders for the Americas Programme, with added support from the Universities of Ottawa, West Indies, and Johns Hopkins. More than 300 fellows have been trained so far. Other initiatives in the region, such as the Caribbean branch of the US Cochrane Centre, which was established in 2013 in Jamaica, and the Caribbean Public Health 
Agency are also providing training in knowledge synthesis and translation.

An evaluation and impact assessment report of capacity building activities in the Caribbean over the past decade documented progress in team building and developing institutional research frameworks. ${ }^{13}$ The report recognised the need to promote collaborative engagement among research and health practitioners and to optimise both human and financial resources through partnerships among Caribbean and North American institutions and global initiatives.

\section{Fostering leadership and networking}

Research networks are an efficient way to combine different disciplines and expertise to address relevant public health problems and promote high quality research. A WHO report ${ }^{14}$ identified that successful collaboration was related to shared goals among network members, clear governance structure, strong leadership, good management practices, sustained resources, and effective communication.

Social network analysis has been used to map relations between members of research networks, identifying central and influential members. ${ }^{15}$ A review of the dengue research network showed the uneven geographical distribution of research activities and near absence of engagement of the private sector, an important strategic gap in efforts to develop new approaches to tackle the growing dengue epidemic. ${ }^{16}$

Much can be learnt from the recent Zika microcephaly epidemics in north eastern Brazil. Leadership and networking were essential for sharing information, generating and disseminating new data, and defining strategic lines of research to respond to the emergency. The rapid discovery of its aetiology and the development of case management routines were facilitated by the cross-disciplinary approaches and interinstitutional collaboration of the microcephaly epidemic research group (box 1).

\section{Research on programme implementation}

One of the main messages of the second Latin American conference on research and innovation for health in $2011^{6}$ was that innovation in research is not measured by the complexity of an intervention or solution to a problem. Innovative research may lead to simple solutions that address large social and economic burdens on the health systems. This is particularly relevant in implementation research.

Implementation research is a rapidly growing area of interest in LAC, geared towards understanding both the determinants of success and barriers to the sustainable introduction or scaling-up health strategies and technologies. ${ }^{18}$
Box 1: Research response to the congenital Zika syndrome epidemic in Brazil

- Response to the 2016 Zika infection epidemic involved national and state surveillance systems, the scientific community, and PAHO. Political support and funding were mobilised, with healthcare providers and the general public having high expectations.

- An interinstitutional microcephaly epidemic research group (MERG) designed and conducted a case-control study to explore possible risk factors associated with the increased incidence of microcephaly. ${ }^{17}$ These findings led to testing of 2 day old infants for Zika infection.

- Social networks helped warn about the problem but also spread unfounded rumours causing confusion about viral aetiology, vector transmission, and potential spread of the disease. The declaration of a state of emergency by the Brazilian authorities and WHO was a turning point for mobilising the public health sector, civil society, and academic community. The scientific community had a leading role in describing the congenital Zika syndrome, formulating its aetiology, and building evidence to inform policy decisions. This resulted in the Zika Preparedness Latin America Network (https:// zikaplan.tghn.org).

\section{Box 2: Improving HPV screening in Latin America-the ESTAMPA study}

- ESTAMPA is led by the WHO International Agency for Research on Cancer in collaboration with various ministries of health in Latin America and with support from the US National Cancer Institute and PAHO. It is enrolling up to 50000 participants to assess the cost effectiveness of implementing different triage methods to detect HPV infection.

- Conducting this large multicountry study has proved to be both challenging and complex, involving a network of scientists, institutions, and governments. Experience has suggested that the best results and highest quality data are largely dependent on effective planning; knowledge of local disease burden; cost-analysis for rolling out study sites; analysis of local potential for scaling up; community engagement; and interdisciplinary management.

- Because implementation research is an emerging field and training opportunities within academic institution are still being scaled up, WHO and the Special Programme for Research and Training in Tropical Disease (TDR) have developed an open online course targeted at researchers and health implementers. The aim of the course is to position implementation research as an important approach to translating innovations into policy by providing readily accessible training in LAC and other WHO regions. ${ }^{19}$

Currently, implementation research is underused in the region, but good examples include the multicentre ESTAMPA study. The study was designed to assess the performance and cost effectiveness of different algorithms and procedures for human papillomavirus (HPV) screening (box 2).

\section{Conclusion}

Research has an important role in sustainable development by improving the performance of health systems and their impact on public health. Science, technology, and innovation are included in several UN sustainable development goals. ${ }^{20} \mathrm{LAC}$ is committed to achieving these goals, but the growth of the required health research in the region is still uneven. ${ }^{21}$ National health and research systems need to review and align targets, strengthen infrastructures, and monitor mechanisms for gathering reliable data to assess progress in social development.

Contributors and sources: All authors contributed to the planning and writing of the original manuscript. Celina Turchi and Enrique Vázquez provided help with the Zika example in box 1, and Rolando Herrero and Maribel Almonte helped with the study example in box 2 .
Competing interests: We have read and understood BMJ policy on competing interest and declare no competing interests. FZ received research support from the Brazilian National Council for Scientific and Technological Development (CNPq), grants \#458100/2014-5 and \#440231/2015-9.

Provenance and peer review: Commissioned; externally peer reviewed.

This article is part of a series proposed by PAHO and commissioned by The BMJ, which peer reviewed, edited, and made the decision to publish the article with no involvement from PAHO. Open access fees for the series are funded by PAHO.

Fabio Zicker, specialist in science, technology, and innovation in global health

Luis Gabriel Cuervo, senior adviser for research promotion and development ${ }^{2}$

Luis Alejandro Salicrup, senior adviser for global health research ${ }^{3}$

${ }^{1}$ Centre for Technological Development in Health, Oswaldo Cruz Foundation, Rio de Janeiro, Brazil

${ }^{2}$ Pan American Health Organization/World Health Organization, Washington, DC, USA

${ }^{3}$ Center for Global Health, National Cancer Institute, National Institutes of Health, Bethesda, MA, USA

Correspondence to: FZicker

fabio.zicker@gmail.com

1 World Health Organization. Strategy on research for health. 2012. http://www who int/phi/WHO Strategy_on_research_for_health.pdf 
2 Ghaffar A, Jsselmuiden I, Zicker F. Changing mindsets: research capacity strengthening in low- and middle-income countries. WHO, 2010. http://www.who.int/tdr/publications/documents/ changing_mindsets.pdf

3 Pan American Health Organization/World Health Organization. Policy on research for health. 49th Directing Council, 61st session of the regional committee. 2009. http://www.paho.org/hq/images/ stories/KBR/Research/research\%20policy\%20 on\%20research\%20for\%20health\%20english.pdf

4 World Bank. Research and development expenditure. https://data.worldbank.org/indicator/GB.XPD.RSDV. GD.ZS?locations $=$ XJ

5 Scimago Journal \& Country Rank. (Accessed 16 Oct 2017). http://www scimagojir.com

6 Council on Health Research for Development (COHRED). Report to the second Latin American conference on research and innovation for health, Panama City, 2011. http://www.cohred.org/ publications/cohred-publications/joint-publications/ report-to-the-2nd-latin-american-conference-onresearch-and-innovation-for-health/

7 Ciocca DR, Delgado G. The reality of scientific research in Latin America; an insider's perspective. Cell Stress Chaperones 2017:22:847-52. doi:10.1007/s12192-017-0815-8

8 Alger J, Becerra-Posada F, Kennedy A, Martinelli E, Cuervo LGGrupo Colaborativo de la Primera Conferencia Latinoamericana de Investigación e Innovación para la Salud. [National health research systems in Latin America: a 14-country review (in Spanish).] Rev Panam Salud Publica 2009;26:447-57.
9 Becerra-Posada F, de Snyder NS, Cuervo LG, Montorzi G. Agendas de investigación priorizadas: un recurso estratégico para la salud en América Latina. [Priority research agendas: a strategic resource for health in Latin America.]Rev Panam Salud Publica 2014:36:361-7.

10 World Health Organization. EVIPnet. http://www.who int/evidence/en/

11 World Health Organization. Special programme on research and training in tropical diseases. SORT IT.

12 Ministério da Saúde Brasil. Programa de Pesquisa para o SUS (PPSUS). 2017. http://www.brasil.gov.br/ saude/2017/02/ministerio-da-saude-garante-80dos-recursos-para-pesquisa-no-setor-no-pais

13 Pan American Health Organization/ World Health Organization. Report on strengthening research capacities for health in the Caribbean 2007-2017. 2017. http://iris.paho.org/xmlui/ handle/123456789/34342

14 World Health Organization, Special Programme for Research and Training in Tropical Diseases. Key enabling factors in effective and sustainable research networks. 2016. http://www.who.int/tdr/ publications/research-networks/en/

15 Fonseca BdeP, Sampaio RB, Fonseca MVA, Zicker F. Co-authorship network analysis in health research: method and potential use. Health Res Policy Syst 2016;14:80. doi:10.1186/s12961-016 0104-5

16 Fonseca BdeP, Zicker F. Dengue research networks: building evidence for policy and planning in Brazil. Health Res Policy Syst 2016;14:34. doi:10.1186/ s12961-016-0104-5
17 de Araújo TVB, Rodrigues LC, de Alencar Ximenes RA, et al, investigators from the Microcephaly Epidemic Research Group Brazilian Ministry of HealthPan American Health OrganizationInstituto de Medicina Integral Professor Fernando Figueira State Health Department of Pernambuco. Association between Zika virus infection and microcephaly in Brazil, January to May, 2016: preliminary report of a case-control study. Lancet Infect Dis 2016;16:1356-63. doi:10.1016/ S1473-3099(16)30318-8

18 Peters DH, Adam T, Alonge O, Agyepong IA, Tran N. Implementation research: what it is and how to do it. BMJ 2013;347:f6753. doi:10.1136/bmj.f6753.

19 World Health Organization, Special Programme for Research and Training in Tropical Diseases. New online course on implementation research unde development. TDR News 2015. http://www.who.int/ $\mathrm{tdr} /$ news/2015/new-online-course/en/

20 United Nations. Sustainable development goals: 17 goals to transform our world. http://www.un.org/ sustainabledevelopment/

21 Becerra-Posada F, Minayo M, Quental C, de Haan S. National research for health systems in Latin America and the Caribbean: moving towards the right direction? Health Res Policy Syst 2014;12:13 doi:10.1186/1478-4505-12-13

Cite this as: BMJ 2018;362:k2492

http://dx.doi.org/10.1136/bmj.k2492 (CC BY-NC-ND 3.0 IGO), which permits distribution and reproduction for non-commercial purposes in any medium, provided the original work is properly cited. If you remix, transform, or build upon the material, you may not distribute the modified material. See: https:// creativecommons.org/licenses/by-nc-nd/3.0/igo/ In any reproduction of this article there should not be any suggestion that PAHO or this article endorse any specific organisation or products 